\title{
Content analysis of daily newspapers in the eighth and ninth governments of the Islamic Republic of Iran in terms of books and reading
}

\author{
Batool Rahmani", Fatemeh Noushin Fard \\ Department of Library and Information Science, Science and Research branch, Islamic Azad University (IAU), Tehran, Iran \\ Email address: \\ Batol_rahmany@yahoo.com (B. Rahmani)
}

To cite this article:

Batool Rahmani, Fatemeh Noushin Fard. Content Analysis of Daily Newspapers in the Eighth and Ninth Governments of the Islamic Republic of Iran in Terms of Books and Reading. Humanities and Social Sciences. Vol. 2, No. 6, 2014, pp. 143-147.

doi: $10.11648 /$ j.hss.20140206.12

\begin{abstract}
The research purpose is to investigate the publication of articles, reports, and reviews related to the introduction of books, libraries and reading culture in the daily newspapers (i.e. Information, Iran, Islamic Republic and the Citizen) in the eighth and ninth Governments of the Islamic Republic of Iran in terms of books and reading between 2001and 2009. Newspapers are regarded as one of the most traditional scheduled publications containing news of current events, informative articles and diverse features which are employed as tools to foster public awareness and enhance common knowledge, offering an accurate reflection of social policies, general opinions and widespread interests. Therefore, the authors wanted to investigate whether or not the role of book and reading has been emphasized as major cultural asset along with other important social factors. Results of the data analysis revealed that cultural activities related to the articles and reviews exhibited statistical difference in the eighth and ninth Governments; however, cultural activities related to the introductions and reports in the eighth and ninth governments of the Islamic Republic of Iran didn't indicate any significant difference. Iran Newspaper with cultural activity (98/54) has surpassed other newspapers in the eighth and ninth governments. Moreover, cultural activities during the Book Week and at the Annual Book Exhibition (November and May) reached significantly higher level compared to other months.
\end{abstract}

Keywords: Book Reading Culture, Libraries, Daily Newspapers, the Eighth and Ninth Governments

\section{Introduction}

Book has always been regarded as a main spiritual source of nations and the best tool for communication among different civilizations. It fills the gap between time and place and makes men come to an understanding. Proving to be the most original form of mass media, book takes a substantial and prominent role in developing the human culture. By looking through history it becomes known that great men were great readers than being a great writes or thinkers. As gross national product along with other indices may reveal the economic condition of a country, the number of book readers, number of libraries, the amount of book purchase, and the time spent on books can reveal the position of the country among other nations in development. In fact, the growth of reading books results in library development, which leads to science advancement and innovation. It is clear that if there is no movement towards perfection, it will end up with thought depression and under-development. Society without some instruments like, studying, reading books, magazines could not be developed in social, political, cultural and economic grounds. A journey into the unknown and exploring it would never be completed without carrying out thorough research and studying. (TV and Book Reading among the Children and Adolescents: A Study in Developing Reading Culture and Book Reading among the Society's Children and Adolescents. Jam-e-Jam Paper: 2001).So many scientists, thinkers and philosophers spent precious moments, days and years of patience and pain to bring out books; therefore, they are considered as absolutely invaluable source of knowledge and Spiritual insights. Books as mainstream of culture and tools for generating common knowledge provide us with real power to confront fear of the unknown.

United Nations Educational, Scientific and Cultural Organization (UNESCO) in its meetings and conferences 
defines development through publishing books, studying them, and programming education among the youth in a long-term period. Economic and Social Council (ECOSOC) has also defined book as one of the most key instrument for forward progress (Javadzadeh, 2008).

In today's fast-paced world, newspapers are regarded as one of the most extremely important form of mass media. Despite the development of different types of media technologies and electronic information, the newspapers till remains valuable, as it's known as print media and uses a physical object as a means of sending its information ensures a longer term of stability and validity compared to broadcast media (also known as electronic media) which transmit their information electronically and comprise television, film and radio. Newspapers are regarded as one of the most traditional scheduled publication containing news of current events, informative articles and diverse features which are employed as effective tools to foster public awareness and enhance common knowledge, offering an accurate reflection of social policies, general opinions and widespread interests. Furthermore, a wide variety of material is published in newspapers, including editorial opinions, criticism, persuasion and obituaries which shed light on social and political issues from the viewpoints of experts and critics influencing and shaping the decision process of the public and government.

\section{Theoretical Framework and the Study Background}

In modern era, contrary to the gloomy predictions and the easy accessibility that the electronic media have, and the outreach that they afford, as information can easily be broadcast to many different regions of the world simultaneously and cost-efficiently, books are still judged as worthy and thousands of books are published every year adding more to human intellect and collective wisdom. According to cultural politics and major international organizations such as UNESCO, the number of books published per year and tendency toward reading are main criteria of cultural achievement (Dahl, 2003).

Historical accounts demonstrate that literacy initiative and education traces its roots to the early $20^{\text {th }}$ century. According to lezyak (1997) literacy acquisition develops sooner than what was imagined and is connected to the individual's domestic environment.

Osborne(2008) has carried out a research on the reading culture of American children and adolescents. This research examined the reading culture of 25 main cities of the USA through distributing questionnaires and conducting reviews (Ghobadi, 2009).

Kassow in a study on parents and children in the USA has drawn a comparison between quantity and quality of reading interaction of children and parents. His findings indicated that domestic literacy takes on influential role in the acquisition of literacy, social awareness and emotional maturity.

Clark has also conducted a research on the attitude of English youth toward reading under the influence of family, mates and school. This research has been carried out on over 1600 students and examines the vision and notion of young adults as the main readers of the books. Findings reveal that the majority of young adults $(58 \%)$ can be classified as avid and voracious readers and are keenly interested in reading. What's more, $71 \%$ of young adults are regular readers and female readers consider themselves as more interested in reading than male readers (Ghobadi, 2009).

National Bureau of Statistics in Italy has run its annual multi-purpose research since1993. Based on the research data in 2006, 44.1\% of people over the age of 6 (a total number of 55.189.000 individuals)claimed that in the last 12 months, they have at least read one non-textbook not including the so-called slow reading which was around 12.8 in 2006 (Ghobadi, 2009).

Chal (1994) carried out a research entitled "The Patterns of Readying Amongst Adults". Results revealed that literacy for adults and individuals who have learning problems, if done with different patterns for English language teaching can enable them to read subsequent to a 20 -hour semester.

Sanakr (1992) has done a research entitled "Encouraging Regular Reading Habits". The literature of this study focuses on this issue, that teachers should represent reading encouragement through independent reading in schools. Moreover, Teachers must assess applying various methods of applying this task which includes a class without reading materials. Overall, considering the appropriate length of time, teachers must encourage reading throughout the year.

Fink (1993) in his study "The Habit of Reading, an Area Neglected amongst the Adults". This study showed that a small number of adult readers, don't develop the habit of reading. Furthermore, Getting the habit of reading amongst adults including related materials, equipping the place with reading materials, reading out, encouraging children to read, participating in book reading meetings have been discussed in this research.

Elbero et al. (1995) have carried out a research entitled "practical Reading Problems" in Denmark, the researcher interviewed 1124 adults in terms of reading habits and skills, out of which 245 individuals were individually tested at home, and 6 normal daily texts were used. They found that 3 percent of the participants have severe practical problems with regard to reading while 9 percent suffer from other problems.

In a study conducted by Mehrnoush, entitled "The Role of Libraries in Society Based on Research in Iranian Press"; it was concluded that newspapers have a more extensive coverage of subject matters in terms of libraries and librarianship compared to weekly and monthly magazines. Although librarians are aware of the importance of the press in capturing public attention, they do not utilize them to shape the public attitude toward libraries and do not send the news and the library-related activities to be published in the press.

Norouzi (2003), in his research titled "Evaluation of the 
Level and the Method of Book-Related News in Daily Newspapers" investigated the book-related news coverage in four daily newspapers (Iran, Citizen, Keihan and Information). He concluded that Iran Newspaper and Citizen Newspaper had wider range of book-related news coverage.

YousefiNiya (2001) in his research titled "An Investigation into Cultural Ads in the Newspapers Published in Qajar'sEra with Emphasis on Book Advertisement" investigated the ads' cultural backgrounds in the newspapers published in Qajar's era regarding the quantity (number, print area) and quality (content). He concluded that Akhtar newspaper which was printed outside Iran had the highest number of cultural ads accounting for 34\%; whereas, Sherafat newspaper had the lowest number amounting to $1 \%$.

Mohammadi (1988), in his research run by the Islamic Conduction and Guidance Bureau of Semnan Province titled "An Investigation into the Adolescents and Young Adults' Interest in Book Reading". According to him receiving further education is positively effective in reading non-text books among adolescents and young adults. School teachers occupy prominent role in generating and stimulating the interest among adolescents and young adults. Boys are less interested in reading than girls and book reading is the third item on their agenda subsequent to doing physical exercise and watching TV. While receiving encouragement, adolescents read more books than young adults. TV has exerted the most pronounced effect amongst the mass media, newspapers and magazines are placed as second and third and radio has produced the most minimal effect.

\section{Methods}

The present research is an applied one which has been carried out using content analysis and historical survey which included directly referring to the documents and various issues of daily newspapers namely (Iran, Information, Islamic Republic and Citizen), during $80^{\text {th }}$ (2001-2009) and the related data was gathered with that regard.

\section{Goals of this Study}

1. How many articles, reviews and introductions were related to subjects such as book, libraries and reading culture in the four daily newspapers, namely Information, Iran, Citizen and Islamic Republic during the eighth and ninth governments of Iran from 2001 May to 2005 August and from 2005 June to 2009 May 18,2012 ?

2. Were cultural events such as book week and international book exhibition effective in increasing the number of articles, reports, introductions and book review during the eighth and ninth governments of Iran from 2001 May to 2005 August and from 2005 June to 2009 May 18, 2012?

3. Was there any significant relationship between the number of published daily newspapers namely, Information, Iran, Citizen and Islamic Republic during the eighth and ninth governments of Iran from 2001 May to 2005 August and from 2005 June to 2009 May 18,2012 ?

\section{The Research Findings}

The main research purpose is the content analysis of the daily newspapers in the eighth and ninth governments of the Islamic Republic of Iran in terms of the publication of book and reading-related subject matters. Therefore, the results are presented in the following tables.

Table 1. Nine Statistical Indexes of Average Activity of the Eighth and Ninth Government

\begin{tabular}{llllllll}
\hline Statistical indexes & Mean $\left(8^{\text {th }} \mathbf{G}\right)$ & $\mathbf{S D}\left(8^{\text {th }} \mathbf{G}\right)$ & $\operatorname{mean}\left(\boldsymbol{9}^{\text {th }} \mathbf{G}\right)$ & $\mathbf{S D}\left(\boldsymbol{9}^{\text {th }} \mathbf{G}\right)$ & $\mathbf{t}$ & $\mathbf{d f}$ \\
\hline reports & 12.5 & 11.9 & 13.34 & 10.88 & 0.773 & 399 \\
Book introduction & 15.4 & 7.89 & 14.75 & 8.8 & 0.729 & 399 \\
articles & 0.66 & 1.35 & 0.2 & 0.6 & 4.34 & 396 \\
Book review & 3.6 & 4.25 & 2.25 & 2.8 & 3.74 & 390 \\
total & 32.25 & 19.62 & 30.64 & 16.56 & 0.879 & 0.000 \\
\hline
\end{tabular}

Question: Is there any significant difference between the cultural activities, articles, reports and reviews (in the four daily newspapers namely, Information, Iran, Islamic Republic and Citizen)?

The data presented in the table, is a comparison of means of cultural activities, articles, reports, book reviews and book introductions in four daily, widely-circulated newspapers, namely, Iran, Islamic Republic, Information and Citizen in the eighth and ninth governments. As it can be observed, the mean of authoring article equals to 0.66 ; whereas, the mean of authoring article in the ninth government constitutes 0.2 ; moreover, the mean of publishing report in the eighth and ninth government amounts to 12.5 and 13.34 percent, respectively. In terms of book introduction, it accounts for 15.4 and 14.75 percent, respectively. Overall, the mean of book review compromises 3.6 and 2.25 respectively.

As it can be perceived, the calculated value in the cultural activities related to the "Articles" and" book reviews is significant in the eighth and ninth governments. The Information presented in the table shows that the cultural activities related to the "article authoring" in the eighth government has surpassed the ninth government at $95 \%$ level of significance. Whereas, cultural activity related to "book review" has surpassed the ninth government at $99 \%$ level of significance. The mean of cultural activities such as "reports" and "book introduction" is in the higher level in the eighth government compared to the ninth government. 
However, no significant difference is observed between the two means. Moreover, no significant difference can be observed in the total cultural activities.

Are there any significant differences in four daily newspapers namely, Information, Iran, Islamic Republic and Citizen between the cultural activities (articles, reports, book introductions and book reviews in the eighth and ninth government?

Table 2. Statistical indexes of the Mean of Activities in the Eighth and Ninth Governments

\begin{tabular}{lllll}
\hline Statistical indexes & Mean $\left(8^{\text {th }} \mathbf{G}\right)$ & $\mathbf{S D}\left(8^{\text {th }} \mathbf{G}\right)$ & mean $\left(9^{\text {th }} \mathbf{G}\right)$ & $\mathbf{S D}\left(9^{\text {th }} \mathbf{G}\right)$ \\
\hline Information & 31.32 & 13.07 & 37.07 & 12.55 \\
Iran & 54.98 & 18 & 39.16 & 17.05 \\
Islamic Republic & 19.2 & 13.8 & 17.54 & 14.56 \\
Citizen & 26.7 & 8.53 & 25.48 & 7.14 \\
total & 33.34 & 19.5 & 28.94 & 15.95 \\
\hline
\end{tabular}

The results of Two-way ANOVA revealed that there is a relationship between Iran, information, Citizen and Islamic Republic newspapers in terms of cultural activitiesat0/01level of significance. Further results indicated that Iran Newspaper with cultural activity (98/54) has surpassed other newspapers in the eighth and ninth governments. Findings support statistical difference at 0.05 level of significance with regard to the cultural activity during the eighth and ninth governments. Moreover, results show that the total cultural activity of the newspapers in the eighth government equals 33.34; whereas, it equals to 28.94 in the ninth government. In terms of the interaction of the newspapers' variables, this mean reduces to 36.16 which are significant at the level of 0.01 . were cultural events such as Book Week and International Book Exhibition effective in increasing the number of articles, reports, introductions and book review during the eighth and ninth governments of Iran from 2001 May to 2005 August and from 2005 June to 2009 May 18, 2012.

Table 3. Variance Analysis

\begin{tabular}{lllll}
\hline Source of change & S.S & df & Means of squares & f \\
\hline Newspaper & 44274.18 & 3 & 14757.7 & 78.26 \\
Government & 1009.06 & 1 & 1009.06 & 5.35 \\
Newspaper-Government Interaction & 5755.50 & 3 & 1918.15 & 10.17 \\
Error & 73540.95 & 390 & 188.56 & - \\
Total & 525942 & 398 & - & - \\
\hline
\end{tabular}

Table 4. Statistical indexes of the Mean of Activities in Cultural Events

\begin{tabular}{|c|c|c|c|c|c|c|c|}
\hline Statistical indexes & Mean (April \& November) & SD(April \& November) & mean(other months) & SD(other months) & $\mathbf{t}$ & df & $\mathbf{p}$ \\
\hline reports & 14 & 13.2 & 12.94 & 10.84 & 0.934 & 399 & 0.351 \\
\hline Book introduction & 15.4 & 8 & 14.08 & 9.3 & 1.65 & 399 & 0.098 \\
\hline articles & 0.59 & 1.26 & 0.18 & 0.53 & 4.32 & 399 & 0.000 \\
\hline Book review & 3.4 & 4.11 & 2.14 & 2.86 & 3.77 & 396 & 0.000 \\
\hline total & 33.42 & 20.9 & 29.36 & 17.34 & 2.52 & 396 & 0.025 \\
\hline
\end{tabular}

The data presented in the table compare the mean of cultural activities such as authoring articles, reports, introductions and reviews in four daily newspapers (Information, Iran, Islamic Republic and Citizen)with regard to cultural events (Book Week and International Book Exhibition) in April and November and other months. As observed, the mean of "authoring article" in the above-mentioned newspapers in April and November amounts to 0.59 ; whereas, the mean of printing article in other months constitutes $0.18 \%$. Moreover, the mean of presenting report in the eighth and ninth governments equals 14 and 12.94, respectively. The introduction of books in the eighth and ninth governments amounts to 15.4 and 14.08, respectively. Book review comprises 3.4 and 2.14, in the eighth and ninth governments. As observed in the table, the total calculated value in terms of cultural activity related to "article" and "book review" in April and November is significant as compared to other months. The presented data also demonstrate that cultural activities related to "authoring article" in April and November have surpassed other months at $99 \%$ level of significance. The cultural activity related to "book review" has surpassed in April and November compared to other months. The total mean of cultural activities in April and November is higher than other months at 0.05 level of significance.

\section{Conclusion}

Considering the research results, it can be concluded that cultural activities related to "introduction", "articles" and "reviews" have markedly increased in the eighth government. However, "reports" show a higher growth in the ninth government. Overall, Cultural activities related to "article and reviews" are significant in both governments. Whereas, cultural activities related to "reports" and "introduction" do not reveal any significant difference. The cultural activity related to "authoring article" has surpassed the ninth government at the $95 \%$ level of significance; whereas, the cultural activity "book review" has surpassed the ninth government at the $99 \%$ level of significance. Iran and Information Newspapers were the most culturally active newspapers. Islamic Republic and Citizen didn't differ in the cultural activities. Moreover, Iran Newspaper with cultural activity (98/54) has surpassed other newspapers in the eighth and ninth government. Total cultural activity of the newspapers in the eighth government amounts to 33.34 compared to the 28.94 percent of the ninth government. Cultural activities are higher in April and November 
compared to other months in terms of cultural events (Book Week and International Book Exhibition). Cultural activity related to "authoring article" in May and November has surpassed other months at $99 \%$ of level of significance; whereas, the cultural activity related to "book review" has surpassed other months in May and November at $95 \%$ of level of significance. Overall, the cultural activities of the eighth government have surpassed those of the ninth government.

\section{References}

[1] Amani, G.(2000). The correlational study of reading during childhood adolescence and during adulthood. LIS doctoral dissertation. Tehran, Islamic Azad Uni versity of Science and Research branch.

[2] Chall, J. (1994). Patterns of adult reading. Learning disabilities: A multidisciplinary Journal, 5, (1), 29-33.

[3] Dahl, A. (2003).The history of Book. Translated by Nouri Afshar, S. in collaboration with cultural studies and research center of the Ministry of Culture and Islamic Guidance. Tehran: Kavir.

[4] Elbro, C. (1992). Functional Reading Difficulties in Denmark: A study of Adult Reading of common texts. Reading and Writing. An interdisciplinary journal, 7 (9), 76-257.

[5] Fink, T. (1993). The Habit of Reading a neglected Dimension of Adult Reading Instruction. Adult Education Quarterly, 3, 46-137.

[6] Ghobadi, C., \& Allahyari Fouman, M. (2009).A Survey into the condition of books and book reading throughout the World: Assessing Children and ado lescents in the USA. Researcher: Mary Pope Arzbourn, et al. Tehran: cooperative entrepreneurs of art and culture.
[7] Ghobadi, C., \&AllahyariFouman, M. (2009). A Survey into the condition of books and book reading throughout the World: in Italy, Spain, Albania and Chile. Researchers: Library DellaItaly, Antonio Mer loga. Tehran: cooperative entrepreneurs of art and culture.

[8] Ghobadi, C., \& Allahyari Fouman, M. (2009). A Survey into the condition of books and book reading throughout the World: attitudes of English youth to ward research and studying in the influence of family, peers, and school. Researchers: Christina Clark, Sarah Arzbournand Rudy Ackerman. Tehran: cooperative entrepreneurs, art and culture.

[9] Javadzadeh, M. (2008). Resalat Newspaper. Tehran: Iran.

[10] Mohammadi, Z. (1997). An Investigation into the Interest of Adolescents and Young Adults' Interest in Book Reading.(Research project). Semnan: Bureau of Culture and Islamic Guidance.

[11] Mehrnoush, K. (1978). The Role of Libraries in Society, Based on Research in Iranian Press. Unpublished M.S. Thesis. Shiraz University, Faculty of Literature and Humanities.

[12] Norouzi, N. (2003). Evaluation of the Level and the Method of Book-Related News in Daily Newspapers. LIS master's thesis. Tehran, Islamic Azad University, Science and Research branch.

[13] Sanakr, J. (1992). Encouraging the lifetime Reading habit. Journal of reading, 35 (6), 474-477.

[14] TV and reading in children and adolescents: A study into the role of media in fostering the reading culture amongst the children and adolescents of the society. Jam-e-Jam. (2001).

[15] Yousefiniya, R. (2001). An Investigation into Cultural Ads in the Newspapers Published in Qajar's Era with Emphasis on Book Advertisement. LIS master's thesis. Tehran, Islamic Azad University, Science and Research branch. 